\title{
Discovering the Values of the Islamic Garden
}

\author{
Haza Hanurhaza Md Jania, Nor Zalina Harun ${ }^{b}$ \\ Mazlina Mansorc, Ismawi Zend \\ aPostgraduate, bc Senior Lecturer, dProfessor, \\ Kulliyah of Architecture and Environmental Design, \\ International Islamic University Malaysia \\ hanurhaza@gmail.com
}

\begin{abstract}
This paper aims to investigate the values and the characteristics of the Islamic garden design. It reviews several dimensions of studies that are significant to understand the Islamic garden concept and its characteristics. The outcomes of this research assist in strengthening the understanding towards the importance of protecting and continuing the legacy of the Muslim civilisation.
\end{abstract}

Keywords: Values; Garden; Islamic garden; Physical characteristics

eISSN: 2398-4295 @ 2017. The Authors. Published for AMER ABRA by e-International Publishing House, Ltd., UK. This is an open access article under the CC BY-NC-ND license (http://creativecommons.org/licenses/by-ncnd/4.0/). Peer-review under responsibility of AMER (Association of Malaysian Environment-Behaviour Researchers), ABRA (Association of Behavioural Researchers on Asians) and CE-Bs (Centre for EnvironmentBehaviour Studies), Faculty of Architecture, Planning \& Surveying, UniversitiTeknologi MARA, Malaysia.

https://doi.org/10.21834/ajbes.v2i5.45 


\subsection{Introduction}

The paper investigates the characteristic of the Islamic garden design and how the values can be adapted into a garden design. Islamic garden is the legacy of the Muslim civilisation; hence, this research tends to shed light on the understanding of the term value from an Asian perspective.

Islamic garden is highly associated with the Muslim civilisation, and it is the prominent garden recognised by many researchers and scholars and the influences are well accepted in the garden design throughout the world. According to Seyyed Hossein Nasr et al., (1993) the idea of a garden in Islam is to remind us of the oneness of God, that He is the creator of the universe. The prominent Islamic gardens are established during the Muslim civilisation starting from the seventh century. The influence of the Islamic garden has been adapted in many parts of the world such as in Spain and India. However, due to the modern movement in the 21th century, the idea of the Islamic garden has gradually been overlooked and undervalued (Petruccioli, 1998).

The situation has contributed to the decreasing number of the Islamic garden in a garden design. It has led to several disadvantages towards preserving the value of the Islamic garden, for instance, the loss of the Muslim culture and heritage. Other than that, it would be difficult to recall, adapt and protect the legacy of the Islamic civilisation. Hence, people are unable to adapt the value of the Islamic garden into a garden design and these causes the decreasing number of the Islamic garden adapted in a garden design (Porter, 1986; Germeraad, 1993; Sajjad Kausar, 2005; Solmaz Mohammadzadeh Kive, 2012).

Therefore, the aim of this research is to investigate the value of the Islamic garden and the original physical characteristics of the Islamic garden. Two objectives are embedded in the research that is to identify the definition of values in the Islamic garden and to investigate the characteristics of the Islamic garden design.

\subsection{Literature Review}

The definitions of value vary depending on a field of research. Through the understanding from the dictionary, a value is perceived as a quality of something that is desired by someone because of the degree of its importance and usefulness. As of history point of view, value arises from a ranking, and the classification of the rank is decided by a society based on its importance (Avrami et al., 2000; Andriessen \& Stam, 2005). While in Islamic study, the concept of value in Islam is defined as a standard whereby an action is judged to be right or wrong based on Quran and Sunnah (Waqar Un Nisa Faizi, 2010).

On the other hand, in urban sociology, value has its worth and importance; subject; community and national oriented. It also involves the result of interaction between personal and impersonal elements, and the desired preference and strong belief put into action (Ram, 1999; Bright-man, 2003; Mukherjee, 2005). In behavioural science, a value is perceived as a guiding principle that is persistent through time, and it is evaluated based on 
its importance rank by the society (Rokeach, 1973; Castelfranchi \& Micelia, 1989; Schwartz, 1992; Schwartz \& Bilsky, 1994; Rohan, 2000; Darke \& Dahl, 2003; Weide et al., 2010). Human geography has a wide range of explanation of value. It can be defined as learned, relatively persistent, not necessarily consciously, emotionally charged, and represented moral judgements in preparing human to act (Frey, 1994). Finally, in the field of architecture and landscape architecture, the value usually depends on the degree of how people look and can relate to the design. It is more than just a mere functional, but it can reflect the character and spirit of the place. It is influenced by on the principles of composition, people's need, symbolism or identity and individual artistry of architectural creators (Rappaport, 1969; Thompson, 2000; Royal Institute of Architect, 2011; Paszkowski, 2011; Farah Mohamed, 2014).

It is discovered that all fields of studies almost have a similar definition of value except for Islamic study. Whereby it emphasised the importance, usefulness, involve emotional feeling and it usually relates to the society. Other than that, in five fields of studies that are urban sociology, behavioural science, human geography, architecture and landscape architecture value is perceived as something that will be put into action. In history, behavioural science and human geography value must be something that a consistent and persistent through time.

Those are among the keywords that are repeated mentions in the definitions of value. However, there are slightly different perspectives on value, unlike the others, for instance, in Islamic study and human geography. In both disciplines, they highlight on the moral desire and value is associated with something that is good or bad. While in history and human geography, it acknowledges that value happened consciously or unconsciously. Whereas in Architecture and landscape architecture, it is the only field that explains the design, character and spirit of the place. Therefore, this paper will view value in ways that it describes "the quality of something that is desired by someone or decided by the society based on the degree of its importance and usefulness. The desired preference is consistent, it involves physical and emotionally charged, and the recognition of it is put into action".

\subsection{Islamic Garden}

Islamic garden is a garden that was established during the Islamic civilisation (Ruggles, 2008). The Quran has many references related to a garden. The word garden and its elements have repeatedly been mentioned in the Quran, for instance, the word tree is mentioned 26 times, river 39 times and light 33 times. Hence, the garden that was developed throughout the Islamic civilisation is the metaphor of the garden of paradise as being interpreted by the Quran. It is a garden that is developed on earth as a resemblance of the garden of paradise (Nazia Ansari, 2011). The garden is perceived as an area for reflection, resting and a reminder of the oneness of God (Ruggles, 2008; Nazia Ansari, 2011). 
Formerly, the Islamic garden was designed as the earthly symbol of paradise. The term Islamic garden was first acknowledged during the establishment of the Persian garden in the seventh century (Haaga, 2005, Raheleh Rostami et al., 2015). It is claimed as the basis for the Islamic garden, and the inspiration of the Persian garden has been adopted in several other prominent Islamic gardens (Nazanin Nafizi et al., 2015). Among them are the Moghul gardens in Kashmir, India and the Alhambra and the Generalife, Southern Spain (Germeraad, 1993; Petruccioli 1998; Haaga, 2005). The influence of the Spain garden has spread throughout the world until the 20th century, and the evidence of the influence can be traced, for instance, the revival garden in California and Mexico.

The Islamic garden promotes the concept of simplicity, and; therefore, the sense of the Islamic garden are well adapted to the modern world. Petruccioli (1998) states, the inspiration for the Islamic garden, first catch the attention of the European culture during the 17 th century. The Islamic garden is perceived as one of the seductive symbols of a new exotic world, describes as a place where the novel taste for space and decoration was freely expressed. The influence of the Islamic garden can be seen through the garden design in Florence and the Royal Pavilion in Brighton, England (Clark, 2004). In the 19th century, the expansion of the Islamic garden's influence has become a glamorous fashion whereby it was selected as one of the official architectural styles in the World Fairs (Petruccioli 1998). The influences of the Islamic garden continue throughout the 19th century until the beginning of the 20th century, before it slowly disappears due to the modern movement (Maryam Ahmadi, 2014).

\subsection{Methodology}

This research is based on the qualitative research methodology. The document analysis is adopted to identify the physical characteristic of the Islamic garden. Furthermore, it is to discover the definition of value in the Islamic garden; and how it has affected the adaptation of the Islamic garden in a garden design. According to Mogalakwe (2006), there are two types of document analysis, which are the interpretation of the primary and secondary document. However, for the purpose of this research, it focuses on the secondary documents. The documents are divided into two sections namely; the value of the Islamic garden and the development of the Islamic garden.

\subsection{Results and Discussions}

The findings of this research emphasised on two main aspects that are the value of the Islamic garden and the characteristics of the Islamic garden based on the Quran and the interpretation of paradise. 


\subsection{The Values of the Islamic Garden}

It is discovered that the process of defining the term value is evaluated in four stages. Firstly, it is usually associated with the word importance and society. Secondly, the value is defined based on the degree of its usefulness and importance. Thirdly, value strives for consistency. Fourthly, the value can be seen after people put action on it. The example of an evaluation of a value happened as follows. For instance, the Islamic garden is perceived as an important legacy of the Muslim civilisation. The degree of its usefulness is evaluated through the physical elements of the garden design such as the importance of water elements in the garden design as a source of purification.

The consistency of the reappearance of the water elements in the Islamic garden design can be seen through the establishment of the Persian garden, followed by Al Andalusia and Mughal garden. The development of the Islamic garden concept has started from the seventh century until the present time, and most of the characteristics of the garden design have a similar pattern. Due to the consistency, the value of the Islamic garden concept as a garden design has been one of a garden phenomenon throughout the world. It is being appreciated through the creation and repetition of a garden with an Islamic garden concept.

According to the process, there are four ways identified on how people put value into something. Something in this context can be referred to culture, tradition or an element. It starts with identifying its importance, evaluating the degree of its usefulness, evaluating what is desired by someone and finally recognizing the value through action.

\section{The Characteristics of the Islamic Garden}

Islam is highly associated with the concept of an Islamic garden (Clark, 2004). As stated by Alarslan and Adiloglu (2011), most of the Persian garden design is created to reflect the idea of a garden as described in the Quran. It is discovered that the principles of the Islamic garden are divided into three sections that are philosophical, religion, and symbolism (Haza Hanurhaza Md Jani et al., 2015).

The principles of the Islamic garden assists in finding the physical characteristic of an Islamic garden as described in the Quran. In Surah Muhammad ayah 15, the description of a garden is described as "An image of the Garden which is promised to those who guard against evil: in it there are rivers of water, which will never spoil and rivers of milk whose taste will never change and rivers of wine, delightful to all who drink it, and rivers of honey of undiluted purity; in it, they will have fruit of every kind and forgiveness from their Lord" (Quran47: 15). There is several other description of a garden in the Quran, and the interpretations of it are presented in Table 1.

Table 1: The Descriptions of Garden in the Quran and Persian garden

\begin{tabular}{|l|l|l|}
\hline No & Garden as per described in the Quran & Persian Garden \\
\hline 1 & $\begin{array}{l}\text { In paradise, there flow streams and canals with } \\
\text { golden banks and beds of pearls and rubies, }\end{array}$ & $\begin{array}{l}\bullet \\
\text { - There is the main canal in it. }\end{array}$ \\
\hline
\end{tabular}




\begin{tabular}{|c|c|c|}
\hline & $\begin{array}{l}\text { the soil of which has a smell sweeter than } \\
\text { musk. }\end{array}$ & $\begin{array}{l}\text { visible, and grooves are cut in the bottom of the } \\
\text { canals to cause the water to flow roughly as if it } \\
\text { were flowing over rocks. } \\
\text { - Canals are so designed that the flow of the } \\
\text { water produces a sound. }\end{array}$ \\
\hline 2 & $\begin{array}{l}\text { There is a perpetual shade that is tamed to } \\
\text { move according to the will of man. }\end{array}$ & \multirow{2}{*}{$\begin{array}{l}\text { - A large number of trees are planted for the } \\
\text { sake of shade, and, as a result, the garden } \\
\text { contains arrow walks. }\end{array}$} \\
\hline 3 & $\begin{array}{l}\text { There is no extreme heat from the sun or bitter } \\
\text { cold. }\end{array}$ & \\
\hline 4 & $\begin{array}{l}\text { There are trees that are so green that they } \\
\text { appear to be black. }\end{array}$ & $\begin{array}{l}\text { - A close relation with nature is obtained in a } \\
\text { simple manner. There is no interval or } \\
\text { boundary line between the mansion and the } \\
\text { rest of the garden so that it cannot be seen } \\
\text { where one begins and the other ends. }\end{array}$ \\
\hline 5 & $\begin{array}{l}\text { Mention is made of the names of trees such as } \\
\text { the thornless lotus, tangled myrtle, palm, and } \\
\text { pomegranate. }\end{array}$ & - The planting of rose bushes is frequent. \\
\hline 6 & There are high buildings unique in the world. & $\begin{array}{l}\text { - The area of the garden is surrounded by a } \\
\text { wall. } \\
\text { - There is a mansion or palace in the middle. }\end{array}$ \\
\hline 7 & $\begin{array}{l}\text { The dimensions of paradise may be likened to } \\
\text { the width of the sky and the earth. }\end{array}$ & $\begin{array}{l}\text { - } \quad \text { g garden is laid out on steep ground. } \\
\text { - } \quad \text { The area of the garden is divided into four. } \\
\text { - } \quad \text { The design of the garden is based on the use } \\
\text { of straight lines. }\end{array}$ \\
\hline 8 & $\begin{array}{l}\text { There is an extraordinary abundance of } \\
\text { unforbidden and perennial fruit that may be } \\
\text { freely eaten. }\end{array}$ & $\begin{array}{l}\text { - There are a large number of fruit trees; the } \\
\text { bigger the garden, the more fruit trees are } \\
\text { planted }\end{array}$ \\
\hline
\end{tabular}

(Source: Findings from literature reviews)

The idea of a garden is described in several verses the Quran and the element of water are repeatedly mentioned. For instance, in Surah Al-Baqarah and Al Imran, "Give the good news to those who believe and do right actions that they will have Gardens with rivers flowing under them. When they are given fruit in the Gardens as a provision" (Quran 2:25). In Surah Ali Imran, "...a Garden as wide as the heavens and the earth, prepared for the people who guard against evil...", "...and Gardens with rivers flowing under them..." (Quran 3: 133-136). Other elements such as plants in Surah An-Nisa, "...We will admit them into cool, refreshing shade" (Quran 4:57) and Surah As Saffat, "...sweet fruits and high honour in Gardens of Delight..." (Quran 37:40-49). Allah mentioned on lodging in Surah Al Furqan, "The Companions of the Garden on that Day will have better lodging and a better restingplace" (Quran 25:24). The image of a garden in paradise is portrayed beautifully in the Quran, resulting man to interpret the idea into the design of an Islamic garden design.

\subsection{Conclusion}

This research intends to highlight the value of the Islamic garden. The determination to explore the value is perceived as a process or effort to maintain and protect as well as to 
continue the legacy of the Islamic civilisation. Throughout the research, it is discovered that there are two important factors in protecting the value of the Islamic garden. It is to understand the concept of an Islamic garden and how it is related to Islam as well as the Muslim civilisation. The idea of the first Islamic garden is adopted from the Quran and the interpretation of paradise. The garden is designed to remind us of the oneness of Allah, that $\mathrm{He}$ is the creator of the universe.

The majority of the Islamic garden is developed in the Middle East countries. This research is an attempt to shed light on the importance of preserving and continuing the Islamic garden. It can help to expand our understanding and appreciation of Islamic garden. Besides, this research is to underline the significance of adopting the idea of an Islamic garden into a garden design. As a quote on Islam emphasised that Islam is not just a religion, it is a way of life. Thus, the idea of an Islamic garden should be a universal concept.

\section{References}

Andriessen, D., \& Stam, C. (2005, January). Intellectual capital of the European Union. In McOaster World Congress on the Management of Intellectual Capital and Innovation (pp. 19-21).

Alarslan U. B., \& Adiloglu, F. (2011). Islamic Gardens with a Special Emphasis on the Ottoman Paradise Gardens: The Sense of Place between Imagery and Reality. Online Journal of Communication \& Media Technologies, 1(4).

Avrami, E. C., Mason, R., \& De la Torre, M. (2000). Values and heritage conservation: research report.

Blair, S. S., \& Bloom, J. M. (2003). The mirage of Islamic art: Reflections on the study of an unwieldy field. The Art Bulletin, 85(1), 152-184.

Bilsky, W., \& Schwartz, S. H. (1994). Values and Personality. European Journal of Personality, 8,163-181.

Clark, E. (2004). The art of the Islamic garden. Marlborough: Crowood.

Darke, P. R., \& Dahl, D. W. (2003). Fairness and discounts: the subjective value of a bargain. Journal of Consumer Psychology, 13(3), 328-338.

Farah Mohamed. (2014, October 21). 'Architecture is an Expression of Value'. Retrieved July 5, 2015, from http://www.huffingtonpost.com/2014/10/21/norman-foster-architecture-values_n_6022606.html.

Frey, B. S. (1994). Cultural economics and museum behaviour. Scottish Journal of Political Economy, 41(3), 325335.

Germeraad, P. W. (1993). Islamic traditions and contemporary open space design in Arab-Muslim settlements in the Middle East. Landscape and Urban Planning, 23(2), 97-106.

Haaga, Elin. (2005). Paradise in the Garden: the influence of the Islamic Garden Today. West Looks East: The Influence of Traditional Arab Design on contemporary Western Designers. Retrieved from http://www.mosaicfound.org/sc/cultural_media/wle_Haaga_bio 
Haza Hanurhaza Md Jani., Nor Zalina Harun., Mazlina Mansor., \& Ismawi Zen. (2015). The Value of the Islamic Garden in response to the Local Environment and Garden Design in Malaysia. In Mohamed Yusoff Abbas, Anniz Fazli Ibrahim Bajunid, \& Sharifah Khalizah Syed Othman Thani (Eds.). Developments and Social Behaviours. Paper presented at the $6^{\text {th }}$ Asia Pacific International Conference on Environment-Behaviour Studies, Barcelona School of Architecture, Spain, 30 August -4 September, Malaysia: emAs emAs Resources.

Maryam Ahmadi. (2014). Exploring the impact of religious and pre-Islamic Persian Gardens in the creation of Chahar Bagh Avenue, Isfahan. In Hoxley, M., \& Crabbe, A. (Eds). CADBE Doctoral Student Conference: 2014 Proceedings. Paper Presented at College of Art, Design \& Built Environment, Nottingham Trent University, United State, 9-10 June (pp. 4-17). Nottingham Trent University: CADBE

Miceli, M., \& Castelfranchi, C. (1989). A cognitive approach to values. Journal for the Theory of Social Behaviour, 19(2), 169-193.

Mogalakwe, M. (2006). The use of Document Research Methods in Social Research. African Sociological Review, 10(1), 221-230.

Nazia Ansari. (2011). Origin of Islamic Garden. Retrieved July 5, 2015, from https://www.academia.edu Nazanin Nafizi., Mohamed Yusoff Abbas., \& Sara Nafisi. (2015). The Role of Belief and Religion of Persian Garden. Journal Architecture Engineering Technology, 4 (3), 153.

Petruccioli, A. (1998). Rethingking the Islamic Garden. In Transformation of Middle Eastern Natural Environment: Legacies and Lessons, ed. Jane Coppock and Joseph A. Miller. New Haven: Yale University Press, pp. 349-363.

Porter, W. (1986). Introduction. Proceedings of Seminar Architecture Education in the Islamic World, in the Series Architectural Transformations in the Islamic World, The Aga Khan Award for Architecture, Granada, Spain, 21-25 April 1986. Concept Media Pte Ltd., Singapore.

Royal Institute of British Architect. (2011).

Raheleh Rostami., Hasanuddin Lamit., Seyed Meysam Khoshnava., Rasoul Rostami., \& Muhamad Solehin Fitry Rosley. (2015). Sustainable Cities and the Contribution of Historical Urban Green Soaces: A Case Study of Historical Persian Gardens. Sustainability, 7(10), 13290-13316.

Rapoport, A. (1969). House Form and Culture. New Jersey: Prentice Hall, Englewood Cliffs.

Ruggles, D. F. (2008). Islamic gardens and landscapes. University of Pennsylvania Press.

Rokeach, M. (1973). The nature of human values (Vol. 438). New York: Free press.

Rohan, M. J. (2000). A rose by any name? The values construct. Personality and social psychology review, 4(3), 255-277.

Sajjad Kausar. (2005). Meaning Of Mughal Landscape. In the 10th International Seminar 'Cultural Landscapes in the 21st Century': Newcastle Upon Tyne, 11-15 April.

Solmaz Mohammadzadeh Kive. (2012). The Other Space of Persian Garden. Polymath: An Interdisciplinary Arts and Sciences Journal,2(3), 85-96.

Schwartz, S. H. (1992). Universals in the content and structure of values: Theoretical advances and empirical tests in 20 countries. Advances in experimental social psychology, 25(1), 1-65. 
Md. Jani, H.H., et.al. / Asian Journal of Behavioural Studies, AjBeS, 2(5), Jan /Mar 2017 (p.11-19)

Thompson, I. H. (2000). Ecology, Community and Delight: Sources of values in landscape architecture. Taylor \& Francis.

Waqar Un Nisa Faizi. (2010). The Reflection Of Islamic Values In The Compulsory Subjects Of Social Sciences At Secondary (ix-x) Level In Karachi (Doctoral dissertation, Jinnah University for Women Karachi). 